\title{
ARTICLE
}

Cite this: DOI: $10.1039 / \times 0 \times x 00000 x$

\section{Two Alternative Approaches to Access Mixed Hydride-Amido Zinc Complexes: Synthetic, Structural and Solution Implications $\uparrow$}

Received 00th January 2012, Accepted 00th January 2012

DOI: $10.1039 / \times 0 \times x 00000 x$

www.rsc.org/

\author{
Andrew J. Roberts, ${ }^{a}$ William Clegg, ${ }^{\text {b }}$ Alan R. Kennedy, ${ }^{a}$ Michael R. \\ Probert, ${ }^{\mathrm{b}}$ Stuart D. Robertson ${ }^{\star a}$ and Eva Hevia*a
}

\section{Introduction}

Metal hydride species ${ }^{1}$ are currently at the forefront of metal research due to their widespread utility as reagents for chemical transformations such as deprotonation/metallation and reduction $^{2}$ as well as their potential in other socio-economically important fields such as energy storage. ${ }^{3}$ Of particular importance for the latter application are lightweight, environmentally benign, high-abundance metals as these are more economically viable and have better gravimetric hydrogen storage capacity. Binary metal hydride species, however, have a number of drawbacks such as pyrophoricity and poor solubility (which in turn leads to low reactivity). Consequently, neutral or anionic co-ligands must be incorporated to lower the aggregation state, aiding solubility. Among the most studied of the early main group metal hydrides are those of magnesium and zinc, primarily using either bulky monoanionic ligands such as $\beta$-diketiminate (nacnac) and its derivatives, ${ }^{4}$ or neutral $\mathrm{N}$-heterocyclic carbenes ${ }^{5}$ to sterically protect the metalhydrogen bond (Figure 1). Bimetallic magnesium/alkali-metal hydride clusters have also been reported containing the secondary amido diisopropylamide ${ }^{6}$ or $1,1,1,3,3,3$ hexamethyldisilazide [HMDS, $\left.\mathrm{N}\left(\mathrm{SiMe}_{3}\right)_{2}\right]_{\text {anion. }}{ }^{7}$
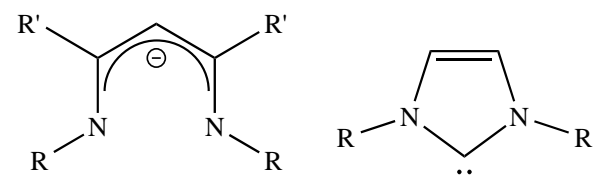

Figure $1 \mathrm{Nacnac}$ anion (left) and N-heterocyclic carbene (right) typically used as aggregation-lowering co-ligands in metal hydride complexes

Running in parallel to this research has been that of the amine boranes $\left(\mathrm{RNH}_{2} \cdot \mathrm{BH}_{3} ; \mathrm{R}_{2} \mathrm{NH} \cdot \mathrm{BH}_{3}\right)$, which contain protic and hydridic hydrogen atoms in close proximity to one another, making them primed for hydrogen release under the correct conditions ${ }^{8}$ as well as precursors for the synthesis of B-N oligomers $^{9}$ and polymers. ${ }^{10}$ Again, the use of main group metals in this area for environmental and economic reasons is pervasive with prominent contributions arising from the groups of Harder, ${ }^{11}$ Hill $^{12}$ and Wright. ${ }^{13}$ While magnesium amidoboranes have been successfully prepared and extensively studied, ${ }^{14}$ zinc amidoboranes have never been reported, 
although Harder has suggested that these are intermediate species on the way to the monomeric zinc hydride complex $\left[\mathrm{CH}\{\mathrm{C}(\mathrm{Me}) \mathrm{N}(\mathrm{Dipp})\}_{2} \mathrm{ZnH}\right]$ which can be obtained in good yields by salt metathesis of $\left[\mathrm{CH}\{\mathrm{C}(\mathrm{Me}) \mathrm{N}(\mathrm{Dipp})\}_{2} \mathrm{ZnCl}\right]$ and a potassium amidoborane. ${ }^{4 c}$

Our interest in this area was stimulated by the excellent recent work of Okuda, ${ }^{5 \text { b-e }}$ and Rivard, ${ }^{5 f}$ who have reported both neutral and cationic NHC-stabilized zinc hydride species (specifically with a focus on alkyl zinc/zinc halide reagents), some of which are effective catalysts for hydrosilylation reactions (Figure 2). Diverging from Harder's approach, these compounds can be prepared using phenylsilanes as hydride sources. Given the considerable carbophilicity of zinc, we surmised that zinc amides [specifically $\mathrm{Zn}(\mathrm{HMDS})_{2}$ ], with their relatively weaker and kinetically activated $\mathrm{Zn}-\mathrm{N}$ bonds (compared to $\mathrm{Zn}-\mathrm{C}$ bonds), ${ }^{15}$ might provide a novel, more facile access point to zinc hydride complexes while also considering that NHCs might stabilize the as yet elusive zinc amido-boranes better than nacnac anions. We present our findings of these studies herein.

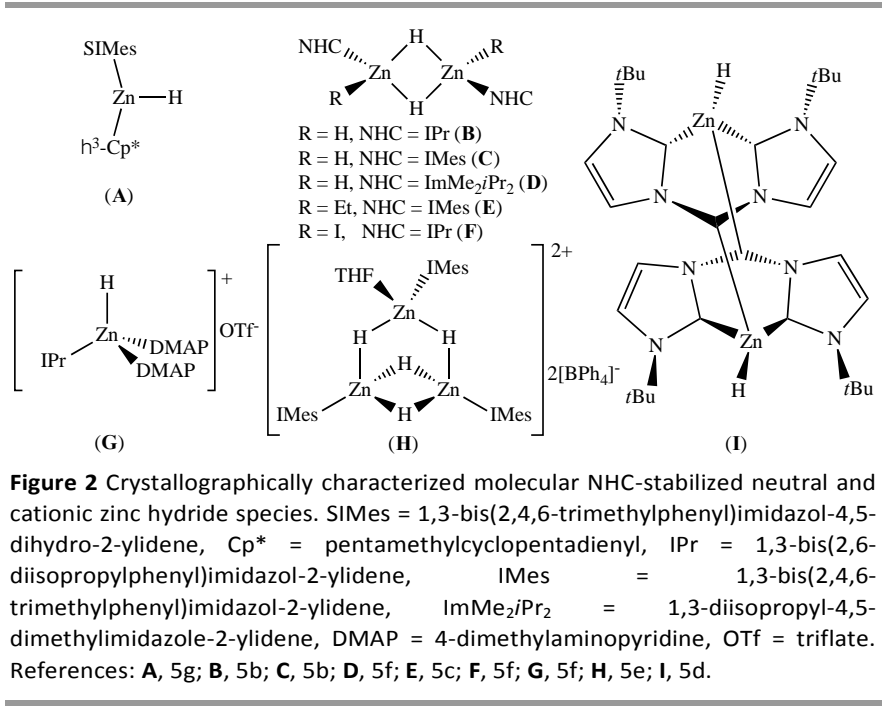

\section{Results and discussion}

We commenced synthetic studies by reacting an equal stoichiometry of dimethylamine borane (DMAB) with $\mathrm{Zn}(\mathrm{HMDS})_{2}$ in THF solution. This mixture immediately precipitated an insoluble white product despite the presence of a vast excess of Lewis donating solvent. Addition of tetramethylethylenediamine (TMEDA), the potentially tetradentate donor tris[2-(dimethylamino)ethyl]amine (Me 6 TREN), or the unsaturared N-heterocyclic carbene IPr (IPr = 1,3-bis(2,6-diisopropylphenyl)imidazol-2-ylidene) did not redissolve this precipitate. However, we did discover that adding a molar equivalent of IPr to the solution of $\mathrm{Zn}(\mathrm{HMDS})_{2}$ prior to the introduction of the amine borane, followed by removal of THF, addition of hexane and reintroduction of THF dropwise with stirring, resulted in a homogenous solution. Storage of this solution at $-30^{\circ} \mathrm{C}$ deposited a small crop of colourless crystals which were revealed by synchrotron single-crystal X-ray diffraction to be the zinc mixed amido-hydrido cluster $\mathrm{Zn}_{4}(\mathrm{HMDS})_{2} \mathrm{H}_{6} \cdot 2 \operatorname{IPr}$ (1) (Scheme 1a and figure 3; note that a non-interacting molecule of THF is present in the crystal structure). This synthesis could be improved by using less polar cyclohexane as the reaction medium, with a larger crop of crystals being deposited upon standing at room temperature. Interestingly, the crystals grown from the cyclohexane solution (that is, in absence of THF) gave essentially the same unit cell parameters as those with the THF molecule of solvation, suggesting its presence is not influencing the crystal packing.

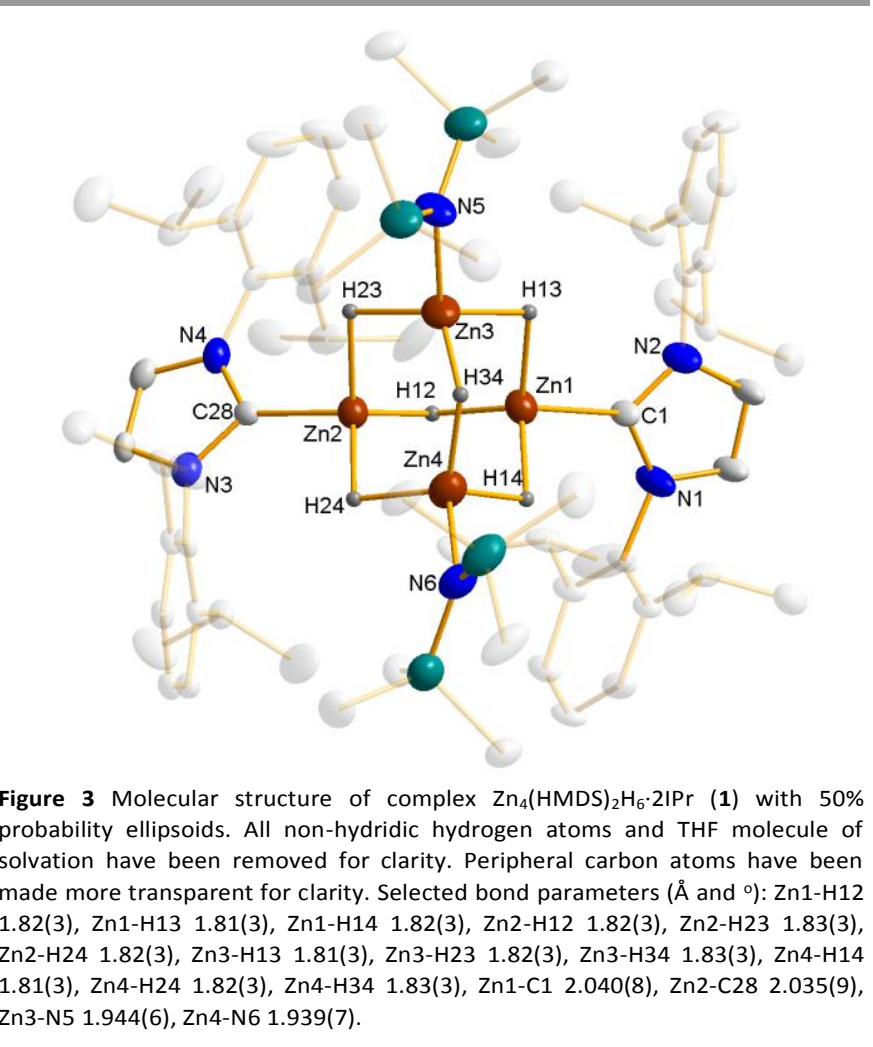

Comprising an adamantyl-like $\left\{\mathrm{Zn}_{4} \mathrm{H}_{6}\right\}^{2+}$ core, this complex can be envisaged as a co-complex of $\operatorname{IPr} \cdot \mathrm{ZnH}_{2}$ and (HMDS)ZnH. Interestingly, although a handful of tetranuclear zinc hydride complexes have been reported, ${ }^{16}$ all of them contain terminal hydride ligands, whereas in $\mathbf{1}$ each hydride is acting as a bridge between two zinc centres such that the core is a tetrahedral $\mathrm{Zn}_{4}$ cluster with the six hydride ligands slightly displaced from the six edges of the tetrahedron. A similar bridging coordination mode has recently been found in the lower nuclearity NHC-stabilized cationic cluster $\left\{\mathrm{Zn}_{3} \mathrm{H}_{4}(\mathrm{IMes})_{3}(\mathrm{THF})\right\}\left\{\mathrm{BPh}_{4}\right\}_{2} .^{.5 e}$ The hydride ligands in $\mathbf{1}$ were located and refined with fixed isotropic displacement parameters, with the only restraint applied on their positions being that the $\mathrm{Zn}-\mathrm{H}$ bonds should be approximately equal in length (which resulted in $\mathrm{Zn}-\mathrm{H}$ bond lengths of $1.82 \pm 0.01 \AA$; the length was not specified as part of the refinement input). This value is marginally longer than the $\mathrm{Zn}-\mathrm{H}-\mathrm{Zn}$ distances reported by Coles for a $\left\{\mathrm{Zn}_{5} \mathrm{H}_{6}\right\}$ cluster (mean $\left.1.775 \AA\right)^{16 \mathrm{~d}}$ and of the bridging hydride-zinc distances in $\mathbf{B}$ (mean $1.712 \AA$ ), $\mathbf{C}$ 
(1.759 ̊), E (mean $1.775 \AA$ ), F (mean $1.78 \AA$ ) and $\mathbf{H}$ [1.65(3)$1.75(4) \AA]$. Zn-C(carbene) and Zn-N(HMDS) bond distances are consistent with other such crystallographically characterized bonds (vide infra).

We note at this juncture that a magnesium analogue of complex $\mathbf{1}$ has been reported previously by Hill and co-workers. ${ }^{5 a}$ The metal-hydride, metal-amide and metal-carbene bond lengths are understandably shorter in our zinc complex compared to the magnesium derivative due to zinc's smaller size (covalent radius $1.22 \AA$ for $\mathrm{Zn} v s 1.41 \AA$ for $\mathrm{Mg}$ ). This is most clearly seen in the $\mathrm{Zn}$-carbene bonds, which have a mean value of $2.038 \AA$, almost $8 \%$ shorter than in the $\mathrm{Mg}$ complex [2.2063(19) $\AA$ ]. The Zn-N (mean $1.966 \AA$ ) and Zn-H (mean $1.82 \AA)$ are marginally shorter than the corresponding $\mathrm{Mg}-\mathrm{N}$ and $\mathrm{Mg}-\mathrm{H}$ bond distances [2.0049(17) and 1.871(mean) $\AA$ respectively]. It is of interest that the magnesium complex was prepared by reaction of $\mathrm{Mg}(\mathrm{HMDS})_{2}$. IPr with phenylsilane at $60^{\circ} \mathrm{C}$. However, when we attempted the preparation of 1 using this approach, we obtained instead a mononuclear mixed hydrido-amido complex (vide infra).

${ }^{1} \mathrm{H}$ NMR spectra of $\mathbf{1}$ in $\mathrm{C}_{7} \mathrm{D}_{8}$ solution exhibit single sets of signals for the IPr, hydride and HMDS groups. DOSY NMR studies showed that all these different ligands present in 1 belong to the same sized species, as the cross points for all their resonances are aligned in the second dimension (Figure S1, average diffusion coefficient $1.19 \times 10^{-9} \mathrm{~m}^{2} \mathrm{~s}^{-1}$ ). The hydride resonance appears as a broad singlet at $3.35 \mathrm{ppm}$, which is just slightly downfield of those recently reported for related dimeric mixed alkyl-hydride zinc species [ ( (IMes) $\left.\mathrm{ZnMeH}\}_{2}\right]$ (at 2.75 ppm). ${ }^{5 c}$ The most informative resonance in the ${ }^{13} \mathrm{C}\left\{{ }^{1} \mathrm{H}\right\}$ NMR spectrum is that for the carbenic carbon which is found at 181.0 ppm, consistent with the retention of the $\mathrm{Zn}-\mathrm{C}_{\text {carbene }}$ interaction in solution. ${ }^{17}$

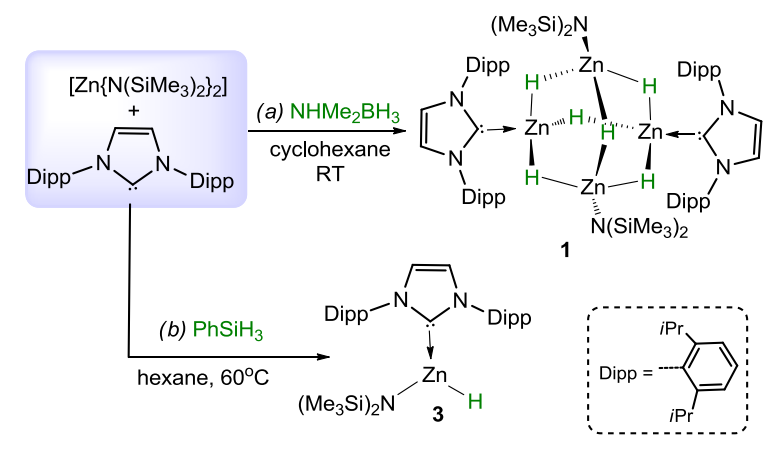

Scheme 1

Considering the heteroleptic constitution of $\mathbf{1}$, we found that this compound could reproducibly be obtained in up to $46 \%$ crystalline yield when the reaction was carried out using a 3:4:2 ratio of DMAB, $\mathrm{Zn}(\mathrm{HMDS})_{2}$ and IPr respectively (see Figures $\mathrm{S} 2$ and $\mathrm{S} 3$ for ${ }^{1} \mathrm{H}$ and ${ }^{13} \mathrm{C}$ NMR spectra). In order to shed some light on the formation of $\mathbf{1}$ and the fate of the original amine borane, multinuclear $\left({ }^{11} \mathrm{~B}\right.$ and $\left.{ }^{1} \mathrm{H}\right)$ NMR studies were carried out on the remaining filtrate from this reaction mixture. The ${ }^{11} \mathrm{~B}$ NMR spectrum (see Figure S4, ESI) revealed the formation of a single boron-containing species displaying a doublet at 33.9 ppm $\left({ }^{1} J_{\mathrm{BH}}=133.8 \mathrm{~Hz}\right)$, consistent with a $\mathrm{BH}$ functionality. ${ }^{18}$ Careful inspection of the ${ }^{1} \mathrm{H}$ NMR spectrum showed two informative singlets at 0.19 and $2.58 \mathrm{ppm}$ along with a broad 1:1:1:1 quartet between 4 and 5 ppm (which reverts to a singlet in the boron-decoupled spectrum at $4.54 \mathrm{ppm}$ ) with a relative integration ratio of 18:6:1 (Figure S5), which allows the tentative assignment of this boron species as the hetero(bisamido)borane [HB(NMe $\left.\left.\mathrm{NM}_{2}\right)(\mathrm{HMDS})\right]$. Supporting this proposed interpretation, GC-MS analysis of the solid residue obtained after removal of volatiles in vacuo showed a series of peaks centred on $\mathrm{m} / \mathrm{z} 216$ with an intensity pattern consistent with that predicted for the molecular ion of this species. Interestingly, a closely related alkyl(amido)borane intermediate has been previously isolated from the thermal decomposition of alkylstrontium amidoborane $\left[\left\{\mathrm{RSr}\left(\mathrm{NMe}_{2} \mathrm{BH}_{3}\right)\right\}_{2}\right] \quad(\mathrm{R}=$ $\left.\mathrm{CH}\left(\mathrm{SiMe}_{3}\right)_{2}\right) .{ }^{12 \mathrm{c}, 14 \mathrm{~b}}$ Building on these studies, we believe that, as similarly proposed by Harder for the synthesis of $\left[\mathrm{CH}\{\mathrm{C}(\mathrm{Me}) \mathrm{N}(\mathrm{Dipp})\}_{2} \mathrm{ZnH}\right]$ (vide supra), initially transient zinc(amido)borane intermediate species (I) must be involved in the formation of $\mathbf{1}$ (scheme 2), which in our case can be obtained by direct deprotonation of DMAB by the zinc amide. This compound must undergo a fast beta-hydride elimination process to form unsaturated and highly reactive $\mathrm{H}_{2} \mathrm{~B}=\mathrm{NMe}_{2}$ along with a mixed amido(hydride)zinc (II). Assuming that cluster $\mathbf{1}$ is obtained as a result of the co-complexation of two different zinc-hydrido species, namely [IPr. $\left.\mathrm{ZnH}_{2}\right]$ and (HMDS)ZnH (vide supra), at this stage it is possible to envisage two alternative reaction pathways for the $\mathrm{BH}_{2}=\mathrm{NMe}_{2}$ species that, as shown in Scheme 2, would explain the formation of bis(amido)borane [HB( $\left.\left.\mathrm{NMe}_{2}\right)(\mathrm{HMDS})\right]$ (III) as the only boron-containing species of this reaction. On one hand and similarly to Hill's investigations on alkylstrontium amidoboranes, this unsaturated species can undergo insertion in the polarized $\mathrm{Zn}-\mathrm{N}$ bond of the amido(hydride)zinc II (pathway a, Scheme 2). ${ }^{19}$ Subsequent boron hydride elimination may lead to the formation of bis(amido)borane III along with $\mathrm{ZnH}_{2}$, which in turn can be trapped by the NHC ligand IPr (as discussed below IPr does not coordinate to the precursor $\mathrm{Zn}(\mathrm{HMDS})_{2}$ ) affording homoleptic hydride $\mathbf{B} .^{5 \mathrm{~b}}$ On the other hand, and under the stoichiometric conditions studied, $\mathrm{BH}_{2}=\mathrm{NMe}_{2}$ can also react with the amine $\operatorname{HMDS}(\mathrm{H})$ produced in the initial step for the formation of $\mathbf{I}$, affording III along with $\mathrm{H}_{2}$ elimination (Scheme 2, pathway b). Support for this second reaction pathway and the concomitant $\mathrm{H}_{2}$ evolution in the formation of $\mathbf{1}$ was obtained by monitoring the reaction of $\mathrm{Zn}(\mathrm{HMDS})_{2} / \mathrm{IPr}$ with DMAB in deuterated cyclohexane by ${ }^{1} \mathrm{H}$ NMR spectroscopy, which showed a sharp singlet at $4.54 \mathrm{ppm}$ which can be assigned to molecular hydrogen. ${ }^{20}$ It should also be noted that, when this reaction was carried out under harsher reaction conditions ( 3 hours at $60^{\circ} \mathrm{C}$ in hexane), the formation of $\mathbf{1}$ is inhibited, affording instead homoleptic dimer [ $\left.\left\{\mathrm{IPrZnH}_{2}\right\}_{2}\right](\mathbf{B})$, which suggests that under these conditions the insertion reaction of $\mathrm{BH}_{2}=\mathrm{NMe}_{2}$ in the $\mathrm{Zn}-\mathrm{N}$ bond of $\mathbf{I I}$ is favoured. 


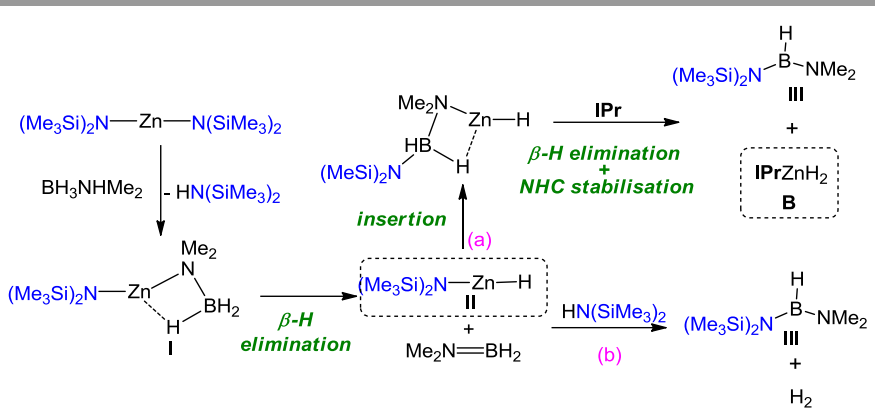

Scheme 2: Proposed pathway for the formation of 1

As mentioned above, an $\mathrm{Mg}$-analogue of $\mathbf{1}$ has been previously prepared, using a $\operatorname{Mg}(\mathrm{HMDS})_{2} \cdot \mathrm{IPr}$ adduct as a precursor. ${ }^{5 \mathrm{a}} \mathrm{In}$ the absence of any characterized NHC adducts of zinc bisamides, ${ }^{21}$ we also focused on the initial step of the reaction, specifically the reaction of $\mathrm{Zn}(\mathrm{HMDS})_{2}$ with IPr. However, we were unable to prepare an IPr-stabilized complex of $\mathrm{Zn}$ (HMDS)2. A ${ }^{1} \mathrm{H}$ NMR spectroscopy study in $d 8$-THF showed that these two reagents do not interact, as shown in Figure S6. This suggests that pre-coordination of the carbene to the metal is not necessary, but rather the free carbene is available in solution to protect the sterically unencumbered metal once the reaction to produce the metal-hydride bond has occurred. This means that the synthesis of clusters such as $\mathbf{1}$ or its $\mathbf{M g}$ derivative can potentially be carried out in a more atomefficient manner, using only half a molar equivalent of NHC per metal (mirroring the stoichiometry of the product, see equation 1) without requiring the preformation of a coordination adduct between the carbene and the relevant metal bisamide.

IPr would appear to be only slightly too sterically encumbered to access the Lewis acidic metal centre of $\mathrm{Zn}(\operatorname{HMDS})_{2}$, as moving to the moderately less bulky carbene IXy [1,3-bis(2,6dimethylphenyl)imidazol-2-ylidene, which bears methyl rather than isopropyl arms at the ortho positions of the flanking aromatic group] resulted in NHC adduct 2 being formed after stirring the two together in hexane/THF at room temperature. Determined by X-ray diffraction studies, the molecular structure of $\mathbf{2}$ is shown in Figure 4.

At 2.100(5) $\AA$, the $\mathrm{Zn}$-carbene distance is at the long end of reported three-coordinate zinc atoms coordinated by an $\mathrm{NHC}^{22}$ as might be expected given our observation that the carbene is only just sterically unencumbered enough to access the zinc centre. The $\mathrm{Zn}-\mathrm{N}$ distances (av. $1.967 \AA$ ) are consistent with $\mathrm{Zn}(\mathrm{HMDS})_{2} \cdot \mathrm{It} \mathrm{Bu}$ (av. $1.957 \AA$ ) and the zinc centre is distorted trigonal planar $\left(\Sigma \angle=360.0^{\circ}\right)$. Compared to free $\mathrm{Zn}(\mathrm{HMDS})_{2}{ }^{23}$ the coordinating carbene understandably forces the N-Zn-N angle from $175.2^{\circ}$ to $123.0(2)^{\circ}$, which is indeed tighter than that seen in the less bulky $\mathrm{I} t \mathrm{Bu}$ adduct $\left[131.4(2)^{\circ}\right] \cdot{ }^{24}$ Likewise, the $\mathrm{Zn}-\mathrm{N}$ bonds are elongated on going from a two-coordinate (av. $1.833 \AA$ ) to a three-coordinate complex (av. $1.967 \AA$ ). The carbene is considerably rotated to minimize steric clashing of the flanking aromatic groups with the silylamide ligands (the $\mathrm{C}_{3} \mathrm{~N}_{2}$ ring plane is oriented at $62.4^{\circ}$ with respect to the $\mathrm{N}-\mathrm{Zn}-\mathrm{N}$ plane).

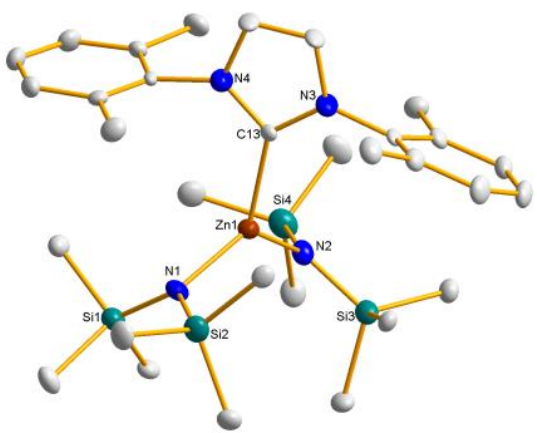

Figure 4 Molecular structure of one of the two crystallographically independent molecules of complex $\mathrm{Zn}(\mathrm{HMDS})_{2} \cdot \mathrm{IXy}$ (2) with $50 \%$ probability ellipsoids. All hydrogen atoms and a disordered THF molecule of crystallisation have been removed for clarity. The second $\mathrm{Zn}(\mathrm{HMDS})_{2} \cdot \mathrm{IXy}$ molecule has disordered HMDS ligands. Selected bond parameters ( $\AA$ and ${ }^{\circ}$ ): Zn1-C13, 2.100(5); Zn1-N1, 1.973(3); Zn1-N2, 1.961(4); N1-Zn1-N2, 123.0(2), N1-Zn1-C13, 119.9(1); N2-Zn1C13, 117.1(2).

In $\mathrm{C}_{6} \mathrm{D}_{6}$ solution, $\mathbf{2}$ appears to maintain its structural composition as evidenced by the marginal downfield shift of the HMDS methyl resonance from 0.20 in free $\mathrm{Zn}(\mathrm{HMDS})_{2}$ to $0.22 \mathrm{ppm}$ in 2 as well as the shift of the methyl and backbone resonances from 2.14 and 6.42 to 2.11 and $5.84 \mathrm{ppm}$. Furthermore, there is the characteristic movement of the carbenic carbon resonance from $218.9 \mathrm{ppm}$ in free IXy to 186.4 ppm when coordinated (see Figures S7 and S8 for full details). We then turned our attention to the reaction of $\mathrm{Zn}(\mathrm{HMDS})_{2}$ with the primary silane $\mathrm{PhSiH}_{3}$ rather than DMAB (Scheme 1b). Equimolar amounts of the two reagents were stirred in hexane at $60^{\circ} \mathrm{C}$ for 3 hours, again in the presence of initially non-interacting IPr. Upon cooling, a crop of crystals of (HMDS)ZnH·IPr (3) were obtained in a 54\% crystalline yield. 3 was characterized by multinuclear NMR spectroscopy $\left({ }^{1} \mathrm{H}\right.$ and ${ }^{13} \mathrm{C}$ ) and $\mathrm{CHN}$ microanalysis. Interestingly, although, under the reaction conditions investigated, it appears that only one of the amido groups of the zinc precursor is activated towards the $\mathrm{Si}-\mathrm{H} / \mathrm{Zn}$-HMDS exchange reaction, when the reaction is carried out using an excess of the silane (5 molar equivalents) or using the more polar solvent THF, the formation of the homoleptic species [\{ $\left.\left\{\mathrm{IPrZnH}_{2}\right\}_{2}\right](\mathbf{B})^{5 \mathrm{~b}}$ occurs preferentially.

$\mathrm{X}$-ray crystallographic studies established the molecular structure of 3 (Figure 5). Contrasting with that previously described for tetranuclear cluster 1, this complex exhibits a monomeric arrangement showing that the combined steric bulk of HMDS and IPr are sufficient to protect and stabilize the three coordinate zinc centre.

Complex 3 is a discrete mononuclear complex with no obvious intermolecular interactions in the solid state. The pronounced steric mismatch of the three ligands around zinc give it a heavily distorted trigonal planar environment. Surprisingly, the largest angle is not that between the two bulkiest ligands, IPr and HMDS [N-Zn-C angle is $125.9(1)^{\circ}$ ] but rather that between HMDS and hydride [126.2(1) $)^{\circ}$. The $\mathrm{Zn}-\mathrm{H}$ bond length of $1.53(3) \AA$ is similar to other terminal zinc-hydride bond distances such as those shown in figure 2 [A, 1.44(3); B, 1.53(2); C, 1.47(4)/1.56(4); D, 1.54(2); I, 1.61(3) ̊̊] and close 
to another mononuclear three-coordinate complex with a terminal Zn-H bond, namely Harder's $\left[\mathrm{CH}\{\mathrm{C}(\mathrm{Me}) \mathrm{N}(\mathrm{Dipp})\}_{2} \mathrm{ZnH}\right][1.46(2) \AA] .{ }^{4 \mathrm{c}}$ The presence of a bulky, labile neutral donor and a non- chelating HMDS ligand may well confer greater latent reactivity on $\mathbf{3}$ with respect to the latter whose chelating monoanionic $\beta$-diketiminate ligand is robust and generally non-reactive.

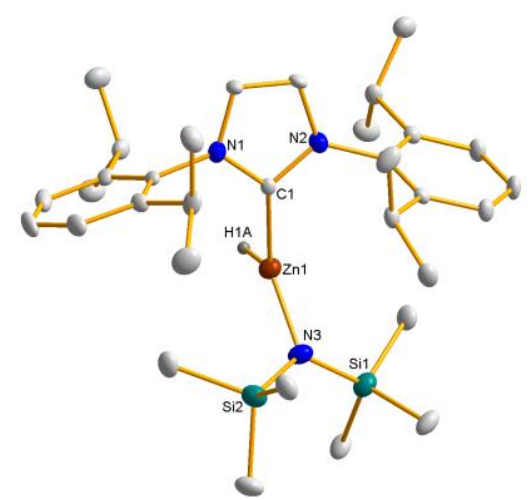

Figure 5 Molecular structure of complex (HMDS) $\mathrm{ZnH} \cdot \operatorname{IPr}(3)$ with $50 \%$ probability ellipsoids. All hydrogen atoms other than zinc-bound hydride have been removed for clarity. Selected bond parameters ( $\AA$ and $\left.{ }^{\circ}\right)$ : Zn1-C1, 2.081(2); Zn1H1A, 1.53(3); Zn1-N3, 1.924(2); C1-Zn1-N3, 125.9(1); C1-Zn1-H1A, 107.9(1); N3Zn1-H1A, 126.2(1).

The ${ }^{1} \mathrm{H}$ and ${ }^{13} \mathrm{C}$ NMR spectra of 3 in $d_{8}$-THF are consistent with the molecular structure. The terminal hydride resonance appears at 3.20 ppm; $c f$ complex $\mathbf{A}, 3.73$ ppm; complex I, 4.14 ppm in $d_{8}$-THF (figure S9 and S10). Interestingly, using the arene solvent $\mathrm{C}_{6} \mathrm{D}_{6}$, which a priori could be considered a much more 'innocent' solvent due to its lesser coordinating ability, the solution behaviour of complex $\mathbf{3}$ is significantly less straightforward (see Figure 6). Focusing on the region around 6 ppm in the ${ }^{1} \mathrm{H}$ NMR spectrum (chosen as the carbene backbone resonance is found here as a clear singlet with no competing resonances nearby), it is clear that there are three distinct carbenes in solution (two of which appear to be coordinated to a metal, corroborated by the ${ }^{13} \mathrm{C}$ NMR spectrum which shows resonances at 191.7 and $180.8 \mathrm{ppm}$, indicative of such coordination). By comparison with the spectra of some known species, we were able to identify two different known species, namely $\mathrm{Zn}(\mathrm{HMDS})_{2}$ and free IPr (Figure 6a). The identity of the other two carbene-containing species was not instantly clear, although one set of carbene resonances was similar to those reported for $\left[\mathrm{ZnH}_{2} \cdot \mathrm{IPr}\right]_{2} .{ }^{5 b} \mathrm{~A}{ }^{1} \mathrm{H}$ DOSY NMR experiment (Figure 6b), ${ }^{25}$ which separates different components in solution according to their diffusion coefficient (and by extrapolation their molecular weight/volume) in a manner which can be considered as 'NMR chromatography', allowed us to definitively assign resonances to each of four components in the solution. A set of resonances corresponding to the molecular structure (HMDS)ZnH.IPr was identified as the final IPr-containing species, leading us to propose that the following equilibrium (equation 2 ) is occurring in solution.

$2(\mathrm{HMDS}) \mathrm{ZnH} \cdot \mathrm{IPr} \rightleftharpoons \mathrm{ZnH}_{2} \cdot \mathrm{IPr}+\mathrm{Zn}(\mathrm{HMDS})_{2}+\mathrm{IPr}$ eq. 2

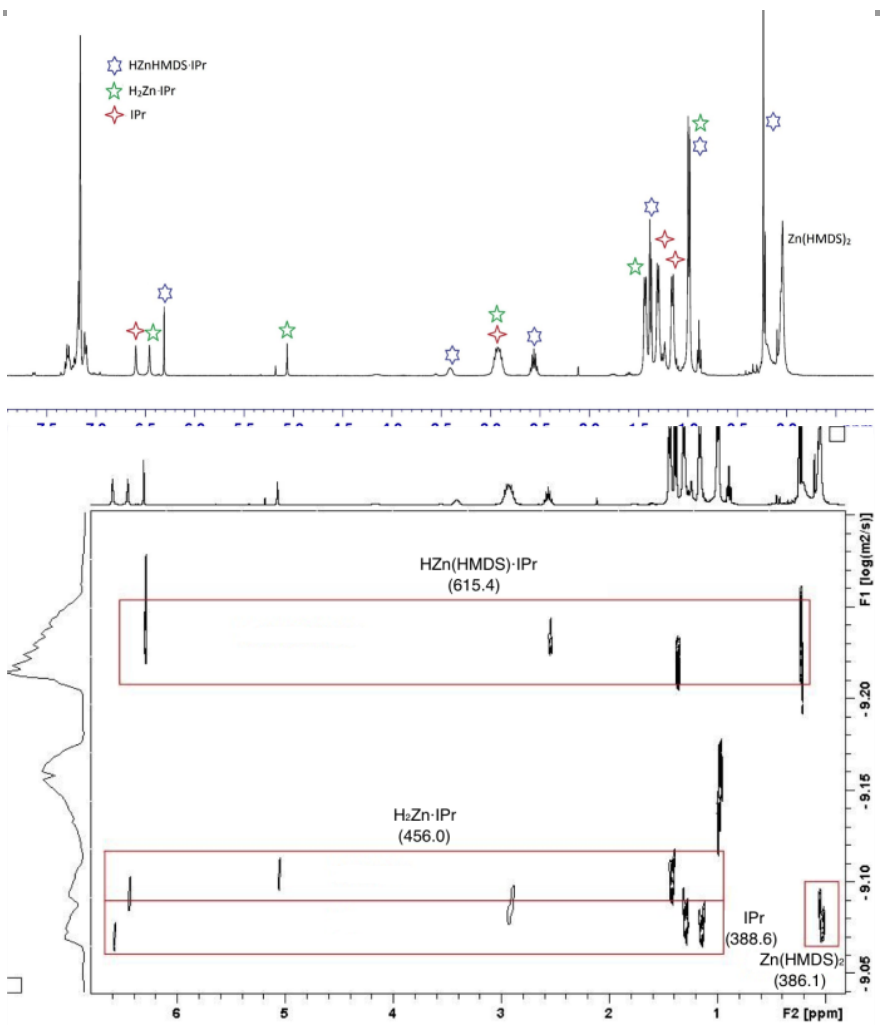

Figure 6 (a, top) ${ }^{1} \mathrm{H}$ NMR spectrum and (b, bottom) ${ }^{1} \mathrm{H}$ DOSY NMR spectrum of crystals of $\mathrm{HZn}(\mathrm{HMDS}) \cdot \operatorname{IPr}(3)$ in $\mathrm{C}_{6} \mathrm{D}_{6}$ solution. Values in parentheses represented the theoretical molecular weight of the quoted species.

This is a simple ligand redistribution from the heteroleptic zinc compound to give two homoleptic compounds, albeit with the presence of four components rather than three since IPr does not coordinate to $\mathrm{Zn}(\mathrm{HMDS})_{2}$ (vide supra). Curiously, in this particular equilibrium the dihydride species does not seem to dimerize to give $\mathbf{B}$, perhaps because the dynamic equilibrium occurs on a faster timescale than the dimerization. This is supported by the DOSY spectrum which suggests that $\mathrm{ZnH}_{2} \cdot \operatorname{IPr}$ (diffusion coefficient $=8.038 \times 10^{-10} \mathrm{~m}^{2} \mathrm{~s}^{-1}$ ) weighs only marginally more than IPr itself (diffusion coefficient $=8.495 \mathrm{x}$ $10^{-10} \mathrm{~m}^{2} \mathrm{~s}^{-1}$ ), and much less than 3 (diffusion coefficient $=5.776$ $\left.\mathrm{x} 10^{-10} \mathrm{~m}^{2} \mathrm{~s}^{-1}\right)$. Furthermore, only one resonance at $5.06 \mathrm{ppm}$ is noticed for the hydrides whereas Okuda's dimer B displays clear resonances for bridging and terminal hydride ligands (at 2.23 and $3.57 \mathrm{ppm}$ in $\mathrm{C}_{6} \mathrm{D}_{6}$ ). This resonance is considerably removed from those in dimer $\mathbf{B}$ and perhaps reflects the change from a four-coordinate zinc in the dimer to a three-coordinate zinc in the monomer. Rivard noted a broad hydride resonance for complex $\mathbf{D}$ at room temperature although this resolved into two distinct resonances below $0^{\circ} \mathrm{C} .{ }^{5 f}$ However, in both cases DOSY NMR spectroscopy showed no hint of monomeric species, suggesting that their fluxional processes go via retention of $\mathrm{Zn}-\mathrm{H}-\mathrm{Zn}$ bridges. A monomer-dimer equilibrium was, however, proposed for complex $\mathbf{E}$ on the basis of variabletemperature NMR spectroscopy. ${ }^{5 \mathrm{c}}$ To further support our equilibrium hypothesis we recorded a ${ }^{1} \mathrm{H}$ NMR spectrum containing authentic $\left[\mathrm{ZnH}_{2} \cdot \mathrm{IPr}\right]_{2}, \mathrm{Zn}(\mathrm{HMDS})_{2}$ and IPr in $\mathrm{C}_{6} \mathrm{D}_{6}$ 
Table 1 Crystallographic data and refinement parameters or complexes $\mathbf{1 , 2}$ and $\mathbf{3}$

\begin{tabular}{|c|c|c|c|}
\hline & 1 & 2 & 3 \\
\hline Empirical formula & $\mathrm{C}_{70} \mathrm{H}_{122} \mathrm{~N}_{6} \mathrm{OSi}_{4} \mathrm{Zn}_{4}$ & $\mathrm{C}_{33} \mathrm{H}_{60} \mathrm{~N}_{4} \mathrm{O}_{0.5} \mathrm{Si}_{4} \mathrm{Zn}$ & $\mathrm{C}_{33} \mathrm{H}_{55} \mathrm{~N}_{3} \mathrm{Si}_{2} \mathrm{Zn}$ \\
\hline Mol. mass & 1437.57 & 698.58 & 615.35 \\
\hline Crystal system & orthorhombic & monoclinic & orthorhombic \\
\hline Space group & $\mathrm{Pna}_{1}$ & $\mathrm{P} 2_{1} / \mathrm{c}$ & $\mathrm{P} 22_{1} 2_{1} 2_{1}$ \\
\hline$a / \AA ̊$ & $22.153(7)$ & $21.938(2)$ & $11.9943(5)$ \\
\hline$b / \AA$ & $16.412(5)$ & $18.8738(14)$ & $13.8275(5)$ \\
\hline$c / \AA$ & $22.139(7)$ & $21.985(4)$ & $21.8642(8)$ \\
\hline$\alpha / /^{\circ}$ & 90 & 90 & 90 \\
\hline$\beta /^{\circ}$ & 90 & $119.304(15)$ & 90 \\
\hline$\gamma /{ }^{\circ}$ & 90 & 90 & 90 \\
\hline$V / \AA^{3}$ & $8049(4)$ & 7938.4(14) & $3626.2(2)$ \\
\hline$Z$ & 4 & 8 & 4 \\
\hline$\lambda / \AA$ & 0.6889 & 0.71073 & 0.71073 \\
\hline$T / K$ & $100(2)$ & $123(2)$ & $123(2)$ \\
\hline Measured reflections & 53956 & 69144 & 13071 \\
\hline Unique reflections & 15103 & 16583 & 7050 \\
\hline$R_{\text {int }}$ & 0.0611 & 0.1095 & 0.0311 \\
\hline Observed rflns $[I>2 \sigma(I)]$ & 12203 & 8990 & 5999 \\
\hline GooF & 1.053 & 1.033 & 1.041 \\
\hline$R$ [on $F$, obs rflns only] & 0.0629 & 0.0700 & 0.0399 \\
\hline $\mathrm{w} R$ [on $F^{2}$, all data] & 0.1767 & 0.1250 & 0.0760 \\
\hline Largest diff. peak/hole e $/ \AA^{-3}$ & $2.74 /-1.22$ & $0.639 /-0.472$ & $0.387 /-0.386$ \\
\hline
\end{tabular}

(that is, we approached the equilibrium from the other side), which revealed a similar spectrum to that previously seen for crystals of $\mathbf{3}$ (see figure $\mathrm{S} 11$ for details). The presence of $\mathrm{Zn}$ (HMDS) 2 is paramount to this deaggregation as it is not witnessed when only IPr is added to $\left[\mathrm{ZnH}_{2} \cdot \mathrm{IPr}\right]_{2}$ (Fig. S11a) but rather only occurs once the $\mathrm{Zn}(\mathrm{HMDS})_{2}$ is added, evidenced by the loss of the two hydride resonances of $\left[\mathrm{ZnH}_{2} \cdot \mathrm{IPr}\right]_{2}$ and the concomitant development of the hydride resonance of $\mathrm{ZnH}_{2} \cdot \mathrm{IPr}$ (fig. S11b).

\section{Experimental}

General experimental All reactions and manipulations were performed under a protective argon atmosphere using either standard Schlenk techniques or a glove box. Hexane and THF were dried by heating to reflux over sodium benzophenone ketyl and then distilled under nitrogen prior to use. Cyclohexane was distilled over $\mathrm{CaH}_{2}$ and stored over $4 \AA$ molecular sieves. DMAB and $\mathrm{PhSiH}_{3}$ were purchased commercially from Sigma-Aldrich and used as received. (HMDS) ${ }_{2} \mathrm{Zn},{ }^{26}$ IXy and $\operatorname{IPr}^{27}$ were prepared by literature methods. NMR spectra were recorded on a Bruker AV 400 $\mathrm{MHz}$ spectrometer operating at $400.13 \mathrm{MHz}$ for ${ }^{1} \mathrm{H}$ and 100.62 $\mathrm{MHz}$ for ${ }^{13} \mathrm{C}$. All ${ }^{13} \mathrm{C}$ spectra were proton decoupled. ${ }^{1} \mathrm{H}$ and ${ }^{13} \mathrm{C}$ spectra were referenced to the residual solvent signal.

X-ray crystallography Crystallographic data were measured on a Rigaku Saturn $724+(\mathbf{1}$, using synchrotron radiation at beamline I19 of Diamond Light Source) or Oxford Diffraction Gemini S laboratory based diffractometer (2 and $\mathbf{3}$, using MoK $\alpha$ radiation). Structures were solved and refined on $F^{2}$ against all independent reflections by the full-matrix leastsquares method using the SHELXS and SHELXL programs. ${ }^{28}$ All non-hydrogen atoms were refined using anisotropic displacement parameters. Hydride scattering factors were used for the 6 bridging $\mathrm{H}$ atoms in the core of complex 1. Selected crystallographic details and refinement details are given in Table 1. CCDC-1042314 to CCDC-1042316 contain the supplementary crystallographic data for this paper. These can be obtained free of charge from the Cambridge Crystallographic Data Centre via www.ccdc.cam.ac.uk/data_request/cif.

\section{Synthesis of $\left[\mathrm{Zn}_{4} \mathrm{H}_{6} \mathrm{HMDS}_{2} \cdot 2 \mathrm{IPr}\right] 1$}

A Schlenk tube was charged with Zn(HMDS)2 (193 mg, 0.5 mmol) and IPr (97 mg, $0.25 \mathrm{mmol})$ to which $5 \mathrm{~mL}$ cyclohexane was added. DMAB (22 $\mathrm{mg}, 0.37 \mathrm{mmol}$ ) was added to this mixture with stirring at room temperature, resulting in a brown homogeneous mixture within 5 minutes. After stirring for 30 minutes at room temperature the stirring was stopped. Crystals were visible within 5 hours. (79 mg, $46 \%$ ). ${ }^{1} \mathrm{H}$ NMR (400.13 $\left.\mathrm{MHz}, 300 \mathrm{~K}, \mathrm{C}_{7} \mathrm{D}_{8}\right) \delta(\mathrm{ppm})=0.13\left(\mathrm{~s}, 36 \mathrm{H}, \mathrm{Si}\left(\mathrm{CH}_{3}\right)_{3}\right), 0.98(\mathrm{~d}$, $\left.24 \mathrm{H}, \mathrm{CH}_{3},{ }^{3} J_{\mathrm{HH}}=6.8 \mathrm{~Hz}\right), 1.34\left(\mathrm{~d}, 24 \mathrm{H}, \mathrm{CH},{ }^{3} J_{\mathrm{HH}}=6.8 \mathrm{~Hz}\right)$, 2.55 (sept, 8H, $i \operatorname{Pr}-\mathrm{CH},{ }^{3} J_{\mathrm{HH}}=6.8 \mathrm{~Hz}$ ), $3.35(\mathrm{~s}, 6 \mathrm{H}, \mathrm{Zn}-H), 6.33$ (s, $4 \mathrm{H}$, imidazole backbone $\mathrm{CH}), 7.14\left(\mathrm{~d}, 8 \mathrm{H}, m-\mathrm{CH},{ }^{3} \mathrm{~J}_{\mathrm{HH}}=7.8\right.$ 
$\mathrm{Hz}), 7.28\left(\mathrm{t}, 4 \mathrm{H}, p-\mathrm{CH},{ }^{3} \mathrm{~J}_{\mathrm{HH}}=7.7 \mathrm{~Hz}\right),{ }^{13} \mathrm{C}\left\{{ }^{1} \mathrm{H}\right\} \mathrm{NMR}(100.62$ $\left.\mathrm{MHz}, 300 \mathrm{~K}, \mathrm{C}_{7} \mathrm{D}_{8}\right) \delta(\mathrm{ppm})=6.5\left(\mathrm{Si}\left(\mathrm{CH}_{3}\right)_{3}\right), 24.0\left(i \mathrm{Pr}-\mathrm{CH}_{3}\right)$, $25.4\left(i \mathrm{Pr}-\mathrm{CH}_{3}\right), 29.0(i \mathrm{Pr}-\mathrm{CH}), 124.8(m-\mathrm{CH}), 124.9$ (NHC$C \mathrm{H}), 131.2(p-C H), 135.1(i-C), 144.9(o-C H), 181.0$ (NHCC).Elemental analysis (\%) for $\mathrm{C}_{66} \mathrm{H}_{114} \mathrm{~N}_{6} \mathrm{Si}_{4} \mathrm{Zn}_{4}$ : calcd: C 58.05, H 8.42, N 6.15; found: C 58.74, H 8.36, N 5.81.

\section{Synthesis of $\mathrm{Zn}(\mathrm{HMDS})_{2} \cdot \mathbf{I X y}$ (2)}

To $\mathrm{Zn}(\mathrm{HMDS})_{2}(193 \mathrm{mg}, 0.5 \mathrm{mmol})$ in $5 \mathrm{~mL}$ of $n$-hexane was added IXy (138 mg, $0.5 \mathrm{mmol})$ and the mixture stirred for 30 minutes at room temperature, yielding a brown mixture. THF was added dropwise until a solution was obtained (approx. 0.3 $\mathrm{mL})$. The solution was stirred for 15 minutes before cooling to $35{ }^{\circ} \mathrm{C}$, giving orange crystals. Removing solvent in vacuo yielded a brown sticky solid presenting identical NMR data. (245 mg, $74 \%$ ). ${ }^{1} \mathrm{H}$ NMR (400 .13MHz, $\left.300 \mathrm{~K}, \mathrm{C}_{6} \mathrm{D}_{6}\right) \delta$ (ppm) $=0.22\left(\mathrm{~s}, 36 \mathrm{H}, \mathrm{Si}\left(\mathrm{CH}_{3}\right)_{3}\right), 2.11\left(\mathrm{~s}, 12 \mathrm{H}, \mathrm{CH}_{3}\right), 5.87(\mathrm{~s}, 2 \mathrm{H}$, imidazole backbone $\mathrm{CH}), 6.92\left(\mathrm{~d}, 4 \mathrm{H}, m-\mathrm{CH},{ }^{3} J_{\mathrm{HH}}=7.6 \mathrm{~Hz}\right)$, $7.02\left(\mathrm{t}, 2 \mathrm{H}, p-\mathrm{CH},{ }^{3} \mathrm{~J}_{\mathrm{HH}}=7.6 \mathrm{~Hz}\right) .{ }^{13} \mathrm{C}\left\{{ }^{1} \mathrm{H}\right\} \mathrm{NMR}(100.62 \mathrm{MHz}$, $\left.300 \mathrm{~K}, \mathrm{C}_{6} \mathrm{D}_{6}\right) \delta(\mathrm{ppm})=7.0\left(\mathrm{Si}\left(\mathrm{CH}_{3}\right)_{3}\right), 19.5\left(\mathrm{CH}_{3}\right), 123.3$ (imidazole backbone $\mathrm{CH}), 129.3(\mathrm{~m}-\mathrm{CH}), 129.9(\mathrm{p}-\mathrm{CH}), 135.9$ $(o-C H), 137.6(i-C), 186.4(\mathrm{NHC}-C)$. Elemental analysis (\%) for $\mathrm{C}_{33} \mathrm{H}_{60} \mathrm{~N}_{4} \mathrm{O}_{0.5} \mathrm{Si} 4 \mathrm{Zn}$ : calcd: $\mathrm{C} 56.74, \mathrm{H}$ 8.66, N 8.02; found: C 57.14, H 9.28, N 8.16.

\section{Synthesis of (HMDS)ZnH·IPr (3)}

A Schlenk tube was charged with $\mathrm{Zn}(\mathrm{HMDS})_{2}$ (193 mg, 0.5 mmol) and $\operatorname{IPr}(194 \mathrm{mg}, 0.5 \mathrm{mmol})$ to which $15 \mathrm{~mL} n$-hexane was added. $\mathrm{PhSiH}_{3}(0.06 \mathrm{ml}, 0.5 \mathrm{mmol})$ was added to this mixture with stirring at room temperature. The mixture was heated to $60^{\circ} \mathrm{C}$ for $3 \mathrm{~h}$, leading to a light brown homogeneous mixture. The reaction was slowly cooled to room temperature, producing a crop of light brown crystals. (116 mg, $54 \%) .{ }^{1} \mathrm{H}$ NMR (400.13 MHz, $300 \mathrm{~K}, d_{8}$-THF) $\delta(\mathrm{ppm})=-0.32(\mathrm{~s}, 18 \mathrm{H}$, $\left.\mathrm{Si}\left(\mathrm{CH}_{3}\right)_{3}\right), 1.08\left(\mathrm{~d}, 12 \mathrm{H}, \mathrm{CH}_{3},{ }^{3} \mathrm{~J}_{\mathrm{HH}}=6.7 \mathrm{~Hz}\right), 1.27(\mathrm{~d}, 12 \mathrm{H}$, $\left.\mathrm{CH}_{3},{ }^{3} J_{\mathrm{HH}}=6.7 \mathrm{~Hz}\right), 2.60\left(\mathrm{~m}, 3 \mathrm{H}, i \mathrm{Pr}-\mathrm{CH},{ }^{3} J_{\mathrm{HH}}=6.8 \mathrm{~Hz}\right), 3.20$ $(\mathrm{s}, 1 \mathrm{H}, \mathrm{Zn}-H), 7.24\left(\mathrm{~d}, 4 \mathrm{H}, m-\mathrm{CH},{ }^{3} J_{\mathrm{HH}}=7.6 \mathrm{~Hz}\right), 7.34(\mathrm{t}, 2 \mathrm{H}$, $\left.p-\mathrm{CH},{ }^{3} J_{\mathrm{HH}}=7.9 \mathrm{~Hz}\right), 7.35(\mathrm{~s}, 2 \mathrm{H}$, imidazole backbone $\mathrm{CH})$. ${ }^{13} \mathrm{C}\left\{{ }^{1} \mathrm{H}\right\}$ NMR $(100.62 \mathrm{MHz}, 300 \mathrm{~K}, d 8$-THF $) \delta(\mathrm{ppm})=6.31$ $\left(\mathrm{Si}\left(\mathrm{CH}_{3}\right)_{3}\right), 24.3\left(i \mathrm{Pr}-\mathrm{CH}_{3}\right), 25.3\left(i \mathrm{Pr}-\mathrm{CH}_{3}\right), 29.4(i \mathrm{Pr}-\mathrm{CH})$, $125.2(m-C H), 126.4(\mathrm{NHC}-\mathrm{CH}), 131.2(p-C \mathrm{H}), 135.9(i-C)$, $145.6(o-C H), 180.3(\mathrm{NHC}-C)$. Elemental analysis $(\%)$ for $\mathrm{C}_{33} \mathrm{H}_{55} \mathrm{~N}_{3} \mathrm{Si}_{2} \mathrm{Zn}$ : calcd: C 64.41, H 9.01, N 6.83; found: C 64.48, H 9.43, N 6.54 .

\section{Conclusions}

Access to two novel and distinct heteroleptic amido(hydride) $\mathrm{Zn}$ species has been gained by reacting a mixture of the zinc bis(amide) $\mathrm{Zn}(\mathrm{HMDS})_{2}$ and the unsaturated $\mathrm{N}$-heterocyclic carbene IPr with two different hydride sources, namely dimethylamino borane (DMAB) and silane $\mathrm{PhSiH}_{3}$. The former affords tetranuclear cluster 1 which can be described as a cocomplex of IPr. $\mathrm{ZnH}_{2}$ and (HMDS) $\mathrm{ZnH}$ and whose formation is likely to occur via a transient $\mathrm{Zn}$ amidoborane species, resulting from the deprotonation of DMAB by the zinc amide precursor.
${ }^{1} \mathrm{H}$ NMR monitoring of the reaction revealed the formation of a single boron species, heteroleptic bis(amido) borane [HB( $\left.\left.\mathrm{NMe}_{2}\right)(\mathrm{HMDS})\right]$ along with $\mathrm{H}_{2}$ evolution. Although the $\mathrm{N}-$ heterocyclic ligand IPr does not bind to $\mathrm{Zn}(\mathrm{HMDS})_{2}$, its presence appears to be crucial for the stabilization of $\mathbf{1}$. Contrastingly, using silane $\mathrm{PhSiH}_{3}$ under harsher reaction conditions, only one of the amido arms of the zinc precursor undergoes $\mathrm{Si}-\mathrm{H} / \mathrm{Zn}$-HMDS metathesis to form (HMDS)ZnH.IPr (3), which exhibits a complex and intriguing behaviour in benzene solutions. These findings illustrate the structural diversity of this family of heteroleptic zinc hydride species as well as their intricate solution chemistry, which can play an important role when assessing their reactivity.

\section{Acknowledgements}

The authors gratefully acknowledge the Royal Society of Edinburgh (BP Trust Fellowship to S.D.R.), the European Research Council (ERC Starting Grant to E.H.), and the EPSRC (grant award no. EP/L027313/1) for their kind sponsorship of this research. We thank Diamond Light Source for access to synchrotron facilities (beamline I19).

\section{Notes and references}

${ }^{a}$ WestCHEM, Department of Pure and Applied Chemistry, University of Strathclyde, Glasgow, G1 1XL, UK.

${ }^{b}$ School of Chemistry, Newcastle University, Newcastle upon Tyne, NE1 7RU, UK.

E-mail: eva.hevia@strath.ac.uk; stuart.d.robertson@strath.ac.uk

$\dagger$ Dedicated to the memory of Professor Ken Wade, a pioneer and an inspiration to Inorganic chemists

Electronic Supplementary Information (ESI) available: NMR spectroscopic data and X-ray data in crystallographic file (CIF) format for compounds 1, 2 and 3. CCDC reference numbers $1042314-1042316$. See DOI: $10.1039 / \mathrm{b} 000000 \mathrm{x} /$

1. S. Aldridge and A. J. Downs, Chem. Rev., 2001, 101, 3305-3365. 2. For an example of the synthesis and utilization of active forms of binary alkali-metal hydrides in metalation and reduction reactions see R. Pi, T. Friedl, P. v. R. Schleyer, P. Klusener and L. Brandsma, J. Org. Chem., 1987, 52, 4299-4303.

3. (a) L. Schlapbach and A. Züttel, Nature, 2001, 414, 353-358; (b) F. Schüth, B. Bogdanovic and M. Felderhoff, Chem. Commun., 2004, 2249-2258; (c) B. Sakintuna, F. Lamari-Darkrim and M. Hirscher, Int. J. Hydrogen Energ., 2007, 32, 1121-1140; (d) I. P. Jain, C. Lal and A. Jain, Int. J. Hydrogen Energ., 2010, 35, 51335144 .

4. (a) H. Hao, C. Cui, H. W. Roesky, G. Bai, H.-G. Schmidt and M. Noltemeyer, Chem. Commun., 2001, 1118-1119; (b) S. P. Green, C. Jones and A. Stasch, Angew. Chem. Int. Ed., 2008, 47, 90799083; (c) J. Spielmann, D. Piesik, B. Wittkamp, G. Jansen and S. Harder, Chem. Commun., 2009, 3455-3456; (d) S. Schulz, T. Eisenmann, D. Schuchmann, M. Bolte, M. Kirchner, R. Boese, J. Spielmann and S. Harder, Z. Naturforsch., 2009, 64b, 1397-1400; (e) S. Harder, J. Spielmann, J. Intemann and H. Bandmann, Angew. Chem. Int. Ed., 2011, 50, 4156-4160.

5. (a) M. Arrowsmith, M. S. Hill, D. J. MacDougall and M. F. Mahon, Angew. Chem. Int. Ed., 2009, 48, 4013-4016; (b) A. Rit, T. P. Spaniol, L. Maron and J. Okuda, Angew. Chem. Int. Ed., 2013, 52, 4664-4667; (c) A. Rit, T. P. Spaniol, L. Maron and J. Okuda, Organometallics, 2014, 33, 2039-2047; (d) A. Rit, T. P. Spaniol and J. Okuda, Chem. Asian J., 2014, 9, 612-619; (e) A. Rit, A. Zanardi, T. P. Spaniol, L. Maron and J. Okuda, Angew. Chem. Int. Ed., 2014, 53, 13273-13277; (f) P. A. Lummis, M. R. 
Momeni, M. W. Lui, R. McDonald, M. J. Ferguson, M. Miskolzie, A. Brown and E. Rivard, Angew. Chem. Int. Ed., 2014, 53, 9347-9351; (g) P. Jochmann and D. W. Stephan, Angew. Chem. Int. Ed., 2013, 52, 9831-9835.

6. P. C. Andrikopolous, D. R. Armstrong, A. R. Kennedy, R. E. Mulvey, C. T. O'Hara and R. B. Rowlings, Eur. J. Inorg. Chem., 2003, 3354-3362.

7. D. J. Liptrot, M. S. Hill and M. F. Mahon, Chem. Eur. J., 2014, 20, $9871-9874$

8. (a) A. Staubitz, A. P. M. Robertson, M. E. Sloan and I. Manners, Chem. Rev., 2010, 110, 4023-4078; (b) A. Staubitz, A. P. M Robertson and I. Manners, Chem. Rev., 2010, 110, 4079-4124.

$9 . \quad$ R. J. Less, R. L. Melen and D. S. Wright, RSC Advances, 2012, 2 , 2191-2199.

10. H. C. Johnson, E. M. Leitao, G. R. Whittell, I. Manners, G. C. Lloyd-Jones and A. S. Weller, J. Am. Chem. Soc., 2014, 136 9078-9093 and references therein.

11. (a) J. Spielmann, G. Jansen, H. Bandmann and S. Harder, Angew. Chem. Int. Ed., 2008, 47, 6290-6295; (b) S. Harder, J. Spielmann and B. Tobey, Chem. Eur. J., 2012, 18, 1984-1991.

12. (a) D. J. Liptrot, M. S. Hill, M. F. Mahon and D. J. MacDougall, Chem. Eur. J., 2010, 16, 8508-8515; (b) M. S. Hill, M. Hodgson, D. J. Liptrot and M. F. Mahon, Dalton Trans., 2011, 40, 77837790; (c) P. Belham, M. S. Hill, D. J. Liptrot, D. J. MacDougall and M. F. Mahon, Chem. Commun., 2011, 47, 9060-9062.

13. (a) H. J. Cowley, M. S. Holt, R. L. Melen, J. M. Rawson and D. S Wright, Chem. Commun., 2011, 47, 2682-2684; (b) M. M. Hansmann, R. L. Melen and D. S. Wright, Chem. Sci., 2011, 2, 1554-1559; (c) R. J. Less, H. R. Simmonds, S. B. J. Dane and D. S. Wright, Dalton Trans., 2013, 42, 6337-6343.

14. (a) J. Spielmann, M. Bolte and S. Harder, Chem. Commun., 2009, 6934-6936; (b) For an excellent overview of the thermal decomposition of magnesium amido-borane complexes see: J. Spielmann, D. F.-J. Piesik and S. Harder, Chem. Eur. J., 2010, 16, 8307-8318; (c) J. Spielmann and S. Harder, Dalton Trans., 2011, 40, 8314-8319; (d) S. Harder, J. Spielmann and J. Intemann, Dalton Trans., 2014, 43, 14284-14290.

$15 . \quad$ D. R. Armstrong, A. M. Drummond, L. Balloch, D. V. Graham, E. Hevia and A. R. Kennedy, Organometallics, 2008, 27, 58605866.

16. (a) M. Krieger, B. Neumüller and K. Dehnicke, Z. Anorg. Allg. Chem., 1998, 624, 1563-1564; (b) W. Marciniak, K. Merz, M. Moreno and M. Driess, Organometallics, 2006, 25, 4931-4933; (c) B. Gutschank, S. Schulz, D. Bläser, R. Boese and C. Wölper, Organometallics, 2010, 29, 6133-6136; (d) For a related $\left\{\mathrm{Zn}_{5} \mathrm{H}_{6}\right\}$ cluster see: M. P. Coles, S. M. El-Hamruni, J. D. Smith and P. B. Hitchcock, Angew. Chem. Int. Ed., 2008, 47, 10147-10150; (e) For a related $\left\{\mathrm{Zn}_{5} \mathrm{H}_{4}\right\}$ cluster see: M. Kahnes, H. Görls, L. González and M. Westerhausen, Organometallics, 2010, 29, 3098-3108.

17. (a) P. L. Arnold, I. J. Casely, Z. R. Turner, R. Bellabarba and R. B. Tooze, Dalton Trans., 2009, 7236-7247; (b) D. R. Armstrong, S. E. Baillie, V. L. Blair, N. G. Chabloz, J. Diez, J. GarciaAlvarez, A. R. Kennedy, S. D. Robertson and E. Hevia, Chem. Sci., 2013, 4, 4259-4266.

18. This chemical shift is close to that of the related species $\left(s \mathrm{Bu}_{2} \mathrm{~N}\right) \mathrm{B}(\mathrm{H})$-HMDS which resonates at $35.2 \mathrm{ppm}$ : W. R. Nutt and R. L. Wells, Inorg. Chem., 1982, 21, 2473-2476.

19. Although the formation of a $\mathrm{Zn}$ bis(amidoborane) intermediate, as the result of the reaction of $\mathrm{Zn}(\mathrm{HMDS})_{2}$ with 2 equivalents of $\mathrm{DMAB}$, cannot be discounted, considering the stoichiometry and mild reaction conditions employed such a scenario sounds unlikely.

$20 . \quad$ G. R. Fulmer, A. J. M. Miller, N. H. Sherden, H. E. Gottlieb, A Nudelman, B. M. Stoltz, J. E. Bercaw and K. I. Goldberg, Organometallics, 2010, 29, 2176-2179.

21. We note that during the preparation of this manuscript the first $\mathrm{NHC}$ adduct of $\mathrm{Zn}(\mathrm{HMDS})_{2}$ was reported, using $\mathrm{I} t \mathrm{Bu}$ as the carbene. See: A. Baishya, M. K. Barman, T. Peddarao and S. Nembenna, J. Organomet. Chem., 2014, 769, 112-118.

22. A search of the CCDB for 3-coordinate zinc(II) bound to an NHC yielded $23 \mathrm{Zn}-\mathrm{C}$ bond lengths in the range 1.981(6) $\left[\left(\mathrm{Ph}_{2} \mathrm{CHO}\right)_{2} \mathrm{Zn} \cdot \mathrm{IPr}\right.$; P. Jochmann and D.W. Stephan, Chem. Eur.
$J ., \quad 2014,20,8370-8378]$ to $2.118(5) \AA\left[t \mathrm{Bu}_{2} \mathrm{Zn} \cdot \mathrm{IPr} ;\right.$ D.R. Armstrong, S.E. Baillie, V.L. Blair, N.G. Chabloz, J. Diez, J. Garcia-Alvarez, A.R. Kennedy, S.D. Robertson and E. Hevia, Chem. Sci., 2013, 4, 4259-4266] with a mean value of $2.056 \AA$.

23. G. Margraf, H.-W. Lerner, M. Bolte and M. Wagner, Z. Anorg. Allg. Chem., 2004, 630, 217-218.

24. It $\mathrm{Bu}$ is reported as being more sterically demanding than IPr in a high coordination number complex but less sterically demanding when the metal has a lower coordination number, such as in Zn(HMDS $)_{2}$. NHC: H. Clavier and S. P. Nolan, Chem. Commun., 2010, 46, 841-861.

25. D. Li, I. Keresztes, R. Hopson and P. G. Williard, Acc. Chem. Res., 2009, 42, 270-280.

26. H. Bürger, W. Sawodny and U. Wannagat, J. Organomet. Chem., 1965, 3, 113-120.

27. L. Hintermann, Beilstein J. Org. Chem., 2007, 3, 22. 